\title{
Paleobiology and philosophy
}

\author{
Adrian Currie ${ }^{1}$
}

Received: 12 February 2019 / Accepted: 1 March 2019 / Published online: 3 April 2019

(c) The Author(s) 2019

\begin{abstract}
I offer four ways of distinguishing paleobiology from neontology, and from this develop a sketch of the philosophy of paleobiology. I then situate and describe the papers in the special issue Paleobiology and Philosophy, and reflect on the value and prospects of paleontology-focused philosophy.
\end{abstract}

Keywords Paleontology $\cdot$ Paleobiology $\cdot$ Historical science

\section{Neontology and paleobiology}

We are paleontologists, so we need a name to contrast ourselves with all you folks who study modern organisms in human or ecological time. You therefore become neontologists (fn 2, Gould 2002).

The philosophy of biology has been, by and large, the philosophy of neontology. 'Neontology' is a term for, well, the non-paleontological parts of biology, the study of currently-living organisms. It is a bespoke notion: by paleontologists, for paleontologists. I think distinguishing neontology from paleobiology is a nice way of introducing the philosophy of the latter, so let's start there. I'll suggest four ways the paleontology/neontology distinction might go, each problematic, but each, I think, bringing some insight. With what the philosophy of paleobiology is under our belts, we can then move on to the papers collected in Paleobiology and Philosophy.

Gould restricts neontology to short time-scales, or to studying modern organisms, reserving deep history to paleobiology. But paleontologists haven't sole proprietary rights to life's deep past. Neontology often involves long temporal scales: for instance, both molecular phylogenetics and adaptationist explanations of extant traits concern events millions of years old. And indeed, some paleobiologists spend a lot of time studying living critters as windows into their extinct subjects. Having said this, the temporal scales and perspectives of paleontology lend themselves more

Adrian Currie

a.currie@exeter.ac.uk

1 University of Exeter, Exeter, UK 
to the study of deep time than the often rather shallow insights we gain from examining our immediate historical neighbourhood. Indeed, although both are sometimes interested in deep time, the processes of interest differ: paleobiologists are interested in 'macro'-evolution and neontologists tend to focus on 'micro'-evolution (Sterelny 2003). Palaeontology's temporal scale is enabled by-and-large from close attention to the fossil record, and this suggests a second approach.

Perhaps what makes the difference between neontology and paleobiology is the latter's focus on the fossil record. This approach is I think my favourite (if I was forced to pick, which I'm not). The fossil-focus comes in part from paleontology's traditional geological home: fossils, after all, are paradigmatically not biological but mineralogical (although sometimes non-fossilized, but still ancient, bones are called 'fossils'). Paleontology (or paleobiology, which as you've already noticed I use with interchangeable abandon) is fundamentally about engaging with, and probing the scale and grain of resolution granted by, the fossil record (Grantham 2004). This involves, then, characterizing those patterns empirically, modelling them, and developing explanatory theories pertaining to them. It also involves developing narratives about aspects of the tree of life, and connecting these with related climatological, geographical and geological events. Neontology is extremely diverse, of course, but when it reaches into the deep past it does so via understanding living critters, often lab-reared, in highly controlled settings - with theory built to match.

When paleobiologists reconstruct the past, then, their starting point is typically the fossil record, and they bring tools, theoretical apparatus and perspectives focused on fossils; neontologists reach into the past using tools, theories and perspectives trained on currently living organisms. The crucial questions in the philosophy of biology arise from neontology: biological individuals and populations, the validity or otherwise of adaptationism, various conceptual puzzles arising from population genetics (the nature of drift and selection, for instance), the nature of species, etc.... All come from, and are examined in terms of, study of living life. They may only contingently arise from such concerns, but their connection to neontology has, I think, made a difference to how those debates play out.

A third pass at a distinction claims paleontology is more properly an historical science than neontology. Neontologists typically utilize the tools of experiment, genetic interventions on model organisms for instance. The fossil record, we might think, doesn't afford such experimental luxury (see Cleland 2002, 2011; Derek Turner 2004, 2007 in particular). There's much to be said about the experimental/historical distinction (I've reservations, to say the least! ${ }^{1}$ ), and characterizing as diverse a set of practices as neontology as fundamentally experimental is, at the very least, an extreme idealization-some pretty impressive payoff would be required, I reckon, to justify it. Having said this, paleobiologists often find themselves in different epistemic situations than neontologists, and at least sometimes the experimental/historical distinction can do some

\footnotetext{
1 See section 1.4 of Currie (under review). Also Jeffares (2008), O’Malley (2016) and Bromham (2016) for more pressure on the distinction.
} 
philosophical work for us. Indeed, discussion of paleontology fits naturally within questions about historical science more generally (Currie and Turner 2016).

Fourth and finally, we can distinguish between paleontology and neontology institutionally (this is my second favourite approach, but first is close-run). Paleontology is an odd beast, science-wise. Her practitioners hail from two disciplines and must integrate them: the formation of mineral structures-geologyand the nature of living organisms - biology. It has also, at least since the 1980s, claimed a subject matter all its own: explaining life's patterns at the grandest scales in terms of macroevolutionary processes (see the papers collected in Sepkoski and Ruse 2009, also Sepkoski 2012). Institutionally, paleontology is equally odd. In universities, paleontology 'departments' don't exist per se, paleontologists are often housed in either biology or geology, but vertebrate paleontologists can be found in medical and veterinary schools (they are prized for their knowledge of anatomy) and those specializing in primates and hominid evolution are often found in anthropology or archaeology. A significant number of paleontologists are based in museums, with the requisite focus on collections and public-facing activities that brings with it. Paleontologists have actively encouraged 'citizen-science' long before citizen-science was a thing: finding, digging up and sorting fossils has long relied upon armies of volunteers. Paleontologists, then, have different training, a home-grown theoretical tool kit, and separate institutional homes from neontologists.

These four distinctions are imperfect, but I think together give something of the flavour of paleontology as opposed to neontology: (1) paleobiologists work at long time scales, neontologists are more temporally immediate; (2) paleobiologists start with fossils, neontologists with living critters; (3) paleobiology is an historical science, neontology an experimental science; (4) paleobiology is done by paleontologists, neontology by biologists. Picking up each thread, philosophers of paleobiology are interested in the nature of macroevolutionary patterns and processes, they are interested in the fossil record and what can be inferred from it, they're interested in the epistemology of deep time, and interested in the theories and practices of paleontologists.

Suitably - considering the messiness of the paleobiology/neontology distinction - the philosophy of paleobiology is not itself a clearly delineated thing. And nor should it be: part of what makes it useful, powerful and interesting is its flexibility and porous boundaries. This collection, I hope, carries on that same spirit. Early versions of most of the papers were presented at the Philosophy of Paleontology in the Badlands workshop in Dinosaur Park, Alberta. It was a wonderful few days and the shape and feel of the collection was established there. I'm grateful to the participants and authors, as well as the referees who volunteered their time and expertise during the process of putting this all together. In the remainder of the paper, I'll introduce and discuss the papers by situating them within the epistemic, conceptual, metaphysical and sociological landscapes that they occupy. I'll close with a little reflection-perhaps a bit aspirational—about the philosophy of paleontology and its promise. 


\section{Underdetermination and the locality of knowledge}

The status of paleontological knowledge is an ongoing preoccupation for philosophers of paleobiology, and historical science more generally. Two themes stand out: first, the apparent underdetermination of many paleontological hypotheses (arising in part from the incompleteness of their evidence, see Turner 2005, 2007) and second, the highly context-dependent strategies and evidential warrants paleontologists adopt (Currie 2018, under review; Wylie 1999; Chapman and Wylie 2016). The fossil record is incomplete and biased, and paleontologists respond flexibly and opportunistically. Paleontological data, and its production and management, is crucial to understanding the nature of paleontological knowledge (Leonelli 2018; Bokulich 2018; Sepkoski 2013). To understand paleobiological reasoning, then, we should attend to those local practices.

Caitlin Wylie's Overcoming the Underdetermination of Specimens draws on her ethnographic work to intervene on how philosophers approach underdetermination, and on how fossil preparation is treated within paleontology. When philosophers consider underdetermination, we think of a relationship between evidence and hypotheses. A hypothesis is underdetermined just when the evidence isn't sufficient to discriminate between it and competitors. But Wylie points out that sometimes the status of evidence as evidence is itself underdetermined. Fossils do not arise from the ground as gorgeous museum pieces: they must be processed-turned into potential evidence-by fossil preperators. These artisans (Wylie 2015) chip rock from fossil, and in doing so, shape the evidential capacities of the completed piece. But the journey from hunk of undifferentiated rock to prepared fossil is a long one, and many choices must be made along the way. As such, the former (rock) underdetermines the latter (specimen). Not only does evidence underdetermine hypothesis, but evidence qua evidence is underdetermined. Wylie works with Sabina Leonelli's distinction between data-potential evidence-and evidence, which is data used to support some hypothesis or another (Leonelli 2016). Examining fossil preparation, we see that not only is evidence underdetermined, but data is as well. Wylie's work captures the contingency of paleontological knowledge-making: specimens are underdetermined by raw material, so decisions early in preparation can make a difference to paleobiological claims far downstream.

Wylie describes a division of labour within paleobiology that serves a critical epistemic function: ensuring preperators don't cook the books in favour of some paleontological hypotheses over others. On the one hand, this division of labour makes good epistemic sense, separating as it does the work of generating data from employing data as evidence.

Few preperators have formally studied anatomy, morphology, or phylogeny; therefore they can't recognise new species or never-before-seen fossil features. Accordingly, scientific theories and debates only minimally inform how preperators prepare a specimen, preventing their inadvertent construction of desired characteristics. (Wylie 2019) 
But on the other hand, this division of labour also hides the ambiguity-the underdetermined nature-of the fossils themselves.

By separating data-makers from knowledge-makers and by omitting the work of datamaking from publications, paleontologists promote the idea that prepared fossils are powerful evidence for their knowledge claims. (Ibid)

The invisibility of fossil preparation serves to promote the apparent objectivity of fossil data, giving the impression that fossils arrive into the world as pristine sources of epistemic power. But this obscures fossils' 'metadata', their history as data, and this in turn obscures their epistemic properties. Drawing inspiration from archaeologists, who frequently worry about this kind of thing (Gero 2007), Wylie calls for better visibility of a specimen's preparation: "that preperators create records of their work as part of each specimen's metadata, which would be accessible in institutions' databases" (Ibid). Wylie's paper adeptly demonstrates the fruitfulness of integrating sociological perspectives with philosophy.

Where Wylie expands underdetermination to include specimen, Thomas Bonnin more finely delineates the various forms of underdetermination between evidence and hypotheses. His Evidential reasoning in historical sciences: applying Toulmin schemas to the case of Archezoa builds a conceptual tool for analysing historical reconstruction that emphasizes the locality, opportunism and contextspecificity of their method. Toulmin schemas are a way of capturing the dynamism of evidential reasoning: claims are made on the basis of warrants, these warrants might be challenged, and those challenges might be rebutted, and so forth. Bonnin analyses the schema through the rise, evolution and fall of 'archezoa', a hypothesized base lineage for eukaryotes which codified a particular story about how multi-cellularity emerged. In following the slow collapse of the hypothesis, Bonnin demonstrates both the conceptual tool and the importance of following the various roles that evidential claims and mediating theory plays in understanding historical reconstruction (see also Chapman and Wylie 2016).

Bonnin criticizes more abstract accounts of historical reconstruction such as Carol Cleland's. Cleland's 'smoking gun' account of historical method characterises paleobiology and related disciplines as a process of generating hypotheses and then searching for new traces (smoking guns) which can discriminate between them (Cleland 2002, 2011). Bonnin argues Cleland's view serves to obscure exactly the warranting theories to which fine-grained attention is required to understand the success (or otherwise) of historical reconstruction. Where the action for Cleland is in the discovery of new traces, Bonnin sees it in the complex interplay between empirical evidence and theory, the scaffolding and speculation required for knowledge production.

This context-specificity is, in my view, the right level of grain to capture the temporally unfolding opportunistic blending of evidential resources that occurs in the appraisal of a given claim. (Bonnin 2019)

Both Wylie and Bonnin's papers demonstrate that explaining paleontological science requires close attention to the practices of those sciences, and that such 
attention can itself pay dividends for a philosophical understanding of science more generally.

\section{Paleontological concepts}

As befitting their institutional, empirical and theoretical autonomy from biology, paleobiologists have developed their own bevy of concepts. And understanding, developing and critiquing scientific concepts, of course, is a main bit of philosophical business. Turner's Paleontology: A Philosophical Introduction (2011) focuses on these conceptual and theoretical issues, as do some of the papers collected here.

Leonard Finkelman's Crossed Tracks: Mesolimulus, Archaeopteryx, and the Nature of Fossils tackles the distinction between body and non-body fossils, and the effects on paleontological systematics, in particular, the growth of parallel taxonomies. In paleobiology the term "Tyrannosaurus rex" is attached to the body-fossil, the remnants of the critter's bones, while a whole other system of nomenclature is used for its trackways and other 'ichnofossils'. These parataxonomies have played a role in philosophical debates before: Derek Turner has used them to motivate pessimism about our capacity to reconstruct the past (as establishing which species taxa left which footprints is incredibly difficult, 2007, pp. 49-51, also see Currie 2018, p. 102 for discussion) and Kim Sterelny and myself cite the parataxonomies as a paleontological means of avoiding idle or unproductive speculation (Currie and Sterelny 2017). However, Finkelman's paper is the first to put parataxonomies in central focus. He argues that although "there are no particular structural or historical features that consistently distinguish body fossils from ichnofossils" (Finkelman 2019), it seems the distinction relies on how the fossils are identified. Part of the story is that ichnofossils are more of the geological realm-they are often employed to explain otherwise confusing geological phenomena-while body fossils are the realm of paleobiologists interested in how the animals lived. This can have practical consequences: Caitlin Wylie has pointed out that often fossil preperators will ignore ichnofossils in favour of body fossils (2019).

Finkelman's strategy is two-fold: he recommends a change to how the taxonomies are structured, and makes a conceptual point about fossil taxa themselves. His argument draws inspiration from paleobotany. Paleobotanists distinguish between plantfossils and fossil plants. The latter are, well, the plants themselves, while the former are the various types of fossils plants leave behind: their seeds, pollen, stems, leaves and so forth. In paleobiology, body fossils are privileged, while in paleobotany they are not. The suggestion, then, is as opposed to identifying body fossils with particular lineages in the past, we should accept that all fossil taxa are in some sense artificial: we should distinguish between animal-fossils and fossil animals.

Derek Turner's In Defense of Living Fossils does what it says on the box: he rehabilitates the notion of 'living fossil'. Basically, living fossils are taxa that have in some sense maintained primitive characteristics: they are living relics of the paleontological past. The notion is often poo-pooed for ignoring the very real changes that these lineages have undergone over evolutionary time-for promoting a false picture of stasis. But Turner is interested in how paleontological theory takes stasis much 
more seriously than neontological theory does. Turner's move is to switch from thinking about living fossils as unchanged species, to being species with unchanged characters. And character stasis is a paleontological explanandum: what is it about evolutionary processes such that we end up with stable characters? Turner's position is not intended to capture the concept as it is currently used, but is explicitly normative and transformational:

Scientific concepts such as "living fossil" have histories; they get put to work in different ways, and for different purposes, at different times... [we should] reappropriate the living fossil concept, putting it to work in a way that reflects going concerns about biodiversity loss. (Turner 2019)

Why biodiversity loss? Turner argues that the value of living fossils in his sense can be understood in terms of phylogenetic diversity. The loss of such phylogenetic misfits, characters that only cluster in a few lineages, is a great one indeed. Turner also makes a novel connection between paleontological value and aesthetics more generally:

... living horseshoe crabs place us into contact with the deep past, in somewhat the same way that actual fossils do. When you see one, you know that creatures rather like this lived on similar beaches hundreds of millions of years ago.

Because paleontological science operates under quite different conditions from sciences that usually drive philosophical reflection on science and values (medical research, for instance), it often makes an interesting target for consideration of both epistemic and non-epistemic values in knowledge production. As we'll see below, this is Havstad's motivation for considering paleontology as well. Turner and Finkelman's contributions each open new arenas for philosophical discussion and stick their conceptual necks out. There's plenty for philosophers to do here.

\section{What shapes paleontological science?}

Many philosophers interested in paleontology want to understand scientific practice. As opposed to analysing the products of paleontology-theories, evidential claims, hypotheses, and so forth - the focus is instead on the processes that lead to those products: fossil gathering, preparing and analysis, hypothesis development, and so on. This leads to questions about why and how paleontologists do what they do: what explains their norms and practices? Although such questions are woven throughout many of the papers in this collection, Joyce Havstad's and Elizabeth Jones' contributions take it as a particular focus.

Joyce Havstad's Let Me Tell You 'Bout the Birds and the Bee-Mimicking Flies and Bambiraptor appeals to paleontological practise and norms in an analysis of species identification. Her central question arises from debate within zoology, and ornithology in particular: in order to identify a new species, do you need to kill specimens? In particular, if a species is already critically endangered, should 
you have to kill some individuals - further endangering the species - in order to scientifically identify it? Havstad identifies a "particularly sharp divide within museum scientists" (Havstad 2019), roughly those with conservation biology as an aim, and those more aligned with collections.

The underlying disagreement here stems from the combination of high stakes and deep uncertainty - from being unsure about how best to observe and preserve certain biological and ecological objects of scientific study that are irreplaceable and yet deeply threatened-plus differing assessments of how best to respond to this deadly combination of risk and uncertainty. (Ibid)

Havstad, though, has a strategy:

Thankfully, there is at least one way to reveal and resolve such underlying disagreements about how to respond to uncertainty while avoiding unhelpful traps: by seeking out contrast cases-especially, ones from areas where the stakes are much lower. (Ibid)

Paleobiology provides Havstad's lower stakes in spades: after all, specimens come pre-killed. And paleontologists will accept the identification of new species on what seems to be very little evidence. Holotypes are often a few scraps of vertebra. Havstad argues, however, that these are not so much differences in standards, but rather that zoologists and paleontologists adopt a common norm, which is indexed to the available evidence. The norm is: "collect as much as you can without redundancy, waste, and violations". Outside of extinction risk, then, Havstad identifies a continuity between specimen collections in both paleontology and zoology. The implication, I take it, is that resolving the debate within zoology requires understanding how that norm interacts with the risks of extinction: how can we reconcile the epistemic norm with the high stakes? Havstad doesn't think there is an easy answer here, "there are good scientific reasons to say both that voucher specimens should and that voucher specimens should not be collected in these difficult and fraught cases" (Havstad 2019).

Elizabeth Jones brings an historian's eye to recent science-in particular the development of ancient DNA techniques, which are currently transforming fields such as archaeology and paleoanthropology (not without raising concerns, Ion 2017). In Ancient Genetics to Ancient Genomics: Celebrity and Credibility in Data-Driven Practice, Jones examines how scientists themselves think about their research and its development, bringing "practitioners' perceptions of datadriven research... into conversation with philosophers' perspectives on the same subject" (Jones 2019). Jones shows how scientist's ideas of what makes for a 'mature science' (namely, being hypothesis-driven) shaped how they conceived of their research field and how their border-work played out.

Jones weaves together interactions between public imagination and experimental feasibility, and between scientists' conceptions of what is properly scientific, the capacities of their new techniques and their hunt for credibility; "how to control contamination and how to control celebrity." Jones emphasizes that these two 
things, celebrity and scientific respectability, are not separate. The basic lesson of Jones' story is that the properly-speaking public and the often cordoned-off zone of scientific expertise simply cannot be pulled apart in understanding science, particularly one as in the public eye as ancient DNA. Funding bodies like the NSF, prestige journals like Nature, and of course the scientists themselves, both exploited and followed the ancient-DNA wave largely fuelled by the success of Jurassic Park. According to Jones, although later ancient DNA research changed in character, being plagued by too much rather than too little data, it was still importantly celebrity driven:

[the] race for the first or the oldest genome (as well as the race to sequence the most genomes) and the accompanying media attention surrounding it, shared striking similarities to the 1990s' search for the first or the oldest DNA. (Jones 2019).

Jones argues that understanding the epistemology of ancient DNA practices requires taking celebrity seriously: "celebrity can be a crucial consideration behind researchers' decisions that influences their process of data gathering, hypothesis testing, technological development, and exploratory experimentation" (Ibid). As Jones says: "celebrity can drive and direct scientific or technological research like data collecting and hypothesis testing can". As we saw in Wylie's paper, Jones combines sociological and historical methods and perspectives in philosophically rich ways. ${ }^{2}$

Havstad and Jones's papers are a powerful argument for philosophers attending to the social conditions, norms and practices of science. Paleontology's institutional character and epistemic situation shapes paleontological research. Just as Bonnin argues that attending to the context-specific details of evidential reasoning is required for understanding historical reconstrucion, these papers add that the social conditions and values in which that reasoning plays out also matters.

\section{At the paleontological scale}

The fossil record affords a powerful view of life at a grand scale, and this enables paleontologists to ask Big Questions about life: its diversity, the factors driving change and maintaining stasis, and-most commonly when philosophers enter the picture-life's contingency or otherwise. Motivated by Stephen Jay Gould's work in Wonderful Life (1990), where he argued that life's path is highly contingent — that if it were 'replayed' we would get very different results - and to an extent Simon Conway-Morris' response Life's Solution (2003), the most developed area of the philosophy of paleontology concerns contingency. Such discussion is closely tied to issues about the autonomy of paleobiology: if at the macroevolutionary scale new dynamics arise, then paleontology could have its own theoretical base (McConwell and Currie 2017; Grantham 2007). This also concerns the nomothetic or idiographic character of paleontology: that is,

\footnotetext{
2 Martin Rudwick's work (1988) is a particularly powerful example of the integration of history and philosophy, and Lukas Rieppel's (2012) examination of museum display practices is a more recent example.
} 
whether paleontological interests are primarily about particulars or generalities (Currie under review section 2.1, Turner 2014).

Alison McConwell continues this rich tradition in her Contingency's Causality and Structural Diversity: Productive and Destructive Aspects of Contingency. She argues that in some contexts contingency is itself a cause of diversity; that the contingency of life at the macroscale should lead us to expect diversity. McConwell builds on John Beatty's work on the evolutionary contingency thesis: that "all distinctively biological generalizations describe evolutionarily contingent states of nature" (Beatty 1995, 46). That is, biological laws are particular and restricted in scope. This connects contingency with another important concern in the philosophy of science: the status of scientific kinds and the laws which are about them. McConwell goes further by arguing that contingency causes pluralism:

If classifying variability into types of kinds distinguished structurally yields a pluralism, then pluralism in the biological domain is explained by the evolutionary contingency thesis. (McConwell 2019)

This is to say, life's striking diversity is explained by life's contingency, and this explains why pluralism (about species, for instance) is so attractive in biology. McConwell ties this thought to Gould's 'decimation' model of evolution. For Gould-particularly in the Cambrian-life's diversity (or 'disparity') didn't increase gradually over time, but rather expanded in great bursts followed by often chancy pruning. McConwell's position is that this process is a contributor to diversity: "not only is diversity production compatible with the decimation model, but contingency's destructive power also contributes to diversity" (Ibid).

Mass extinctions are a locus for paleobiological research, and in my Mass Extinctions as Major Transitions I try to bring that work into dialogue with a largely neontological research program which tackles the conditions under which major biological transitions, such as the evolution of multicellularity, occur. My explanation for the lack of overlap between paleobiology and neontology here is to do with how the research is structured: I think paleontological investigation is 'phenomena-led', that is, the relevance of information turns on its relationship to the phenomena (in this instance, mass extinctions), while the major transitions literature is 'theory-led', the relevance of information turns on its relationship to the theory at hand. Because information from the fossil record is at the wrong grain to really connect with theory about major transitions, it is not relevant. However, I give some reasons to think things are changing in this regard, and further explore how paleobiologists think about major events in life's history, that is, what a 'major transition' looks like for paleontological eyes.

I think one of the most exciting aspects of paleontology is the view it affords of life's history at grand scales. This in turn provides fresh perspectives on the nature of chance, contingency and the historicity of macroevolution. 


\section{A closing note}

I hope this collection of papers demonstrates that the philosophy of paleobiology is now wide open for business: paleontology is a science both rich in its own conceptual, epistemic and metaphysical questions, as well as in source material for reflection on the nature of science and deep history. Paleontological science is naturally synthetic, combining as it does geology and biology, but has also developed its own institutional structures, research practices, and epistemic and methodological strategies. The philosophy of paleontology should take its cue from the source material: combining and engaging with issues in the philosophy of biology and history (and science more generally), but also developing its own set of particular questions and research agendas. Further, this philosophy lends itself to cross-disciplinary engagement. Sociological and historical perspectives fit naturally with the philosophical in this domain, and the openness of paleontologists to discussion with other disciplines has, for myself at least, proven both welcoming and incredibly fruitful.

The majority of biology is neontology, and fair enough too: living life is a rich resource for understanding living systems. But it is also a biased, contingent source of knowledge: what happens to be alive now is a tiny fraction of what has lived, and is in many ways not representative. As such, if you want to understand life, paleontology's scale and breadth is necessary. Similarly, if the philosophy of biology is driven by neontology alone, then it cannot help but inherit that parochial perspective. Although much philosophy of biology is really the philosophy of neontology, there's plenty of room still for the philosophy of paleobiology.

Acknowledgements Many thanks to Derek Turner for reading over a draft. The meeting Philosophy of Paleontology in the Badlands was funded by a SSHRC Connection Grant, and some of the research for this paper was supported by a grant by the Templeton World Charity Foundation.

Open Access This article is distributed under the terms of the Creative Commons Attribution 4.0 International License (http://creativecommons.org/licenses/by/4.0/), which permits unrestricted use, distribution, and reproduction in any medium, provided you give appropriate credit to the original author(s) and the source, provide a link to the Creative Commons license, and indicate if changes were made.

\section{References}

Beatty J (1995) The evolutionary contingency thesis. Concepts Theor Ration Biol Sci 45:81

Bokulich A (2018) Using models to correct data: paleodiversity and the fossil record. Synthese. https:// doi.org/10.1007/s11229-018-1820-x

Bonnin T (2019) Evidential reasoning in historical sciences: applying Toulmin schemas to the case of Archezoa. Biol Philos. https://doi.org/10.1007/s10539-019-9677-z

Bromham L (2016) Testing hypotheses in macroevolution. Stud Hist Philos Sci Part A 55:47-59

Chapman R, Wylie A (2016) Evidential reasoning in archaeology. Bloomsbury Publishing, London

Cleland CE (2002) Methodological and epistemic differences between historical science and experimental science. Philos Sci 69(3):447-451

Cleland CE (2011) Prediction and explanation in historical natural science. Br J Philos Sci 62(3):551-582 
Conway-Morris S (2003) Life's solution: inevitable humans in a lonely universe. Cambridge University Press, Cambridge

Currie A (2018) Rock, bone, and ruin: an optimist's guide to the historical sciences. MIT Press, Cambridge

Currie A (2019) Mass extinctions as major transitions. Biol Philos. https://doi.org/10.1007/s1053 9-019-9676-0

Currie A (under review) History matters: knowledge and the deep past

Currie A, Sterelny K (2017) In defence of story-telling. Stud Hist Philos Sci Part A 62:14-21

Currie A, Turner D (2016) Introduction: scientific knowledge of the deep past. Stud Hist Philos Sci 55:43

Finkelman L (2019) Crossed tracks: Mesolimulus, Archaeopteryx, and the nature of fossils. Biol Philos. https://doi.org/10.1007/s10539-019-9680-4

Gero JM (2007) Honoring ambiguity/problematizing certitude. J Archaeol Method Theory 14(3):311-327

Gould SJ (1990) Wonderful life: the Burgess Shale and the nature of history. WW Norton \& Company, New York City

Gould SJ (2002) The structure of evolutionary theory. Harvard University Press, Cambridge

Grantham T (2004) The role of fossils in phylogeny reconstruction: why is it so difficult to integrate paleobiological and neontological evolutionary biology? Biol Philos 19(5):687-720

Grantham T (2007) Is macroevolution more than successive rounds of microevolution? Palaeontology 50(1):75-85

Havstad JC (2019) Let me tell you bout the birds and the bee-mimicking flies and Bambiraptor. Biol Philos. https://doi.org/10.1007/s10539-019-9681-3

Ion A (2017) How interdisciplinary is interdisciplinarity? Revisiting the impact of aDNA research for the archaeology of human remains. Curr Swed Archaeol 25:177-198

Jeffares B (2008) Testing times: regularities in the historical sciences. Stud Hist Philos Sci Part C Stud Hist Philos Biol Biomed Sci 39(4):469-475

Jones ED (2019) Ancient genetics to ancient genomics: celebrity and credibility in data-driven practice. Biol Philos. https://doi.org/10.1007/s10539-019-9675-1

Leonelli S (2016) Data-centric biology: a philosophical study. University of Chicago Press, Chicago

Leonelli S (2018) The time of data: timescales of data use in the life sciences. Philos Sci 85(5):741-754

McConwell AK (2019) Contingency's causality and structural diversity. Biol Philos. https://doi. org/10.1007/s10539-019-9679-X

McConwell AK, Currie A (2017) Gouldian arguments and the sources of contingency. Biol Philos 32(2):243-261

O’Malley MA (2016) Histories of molecules: reconciling the past. Stud Hist Philos Sci Part A 55:69-83

Rieppel L (2012) Bringing dinosaurs back to life: exhibiting prehistory at the American Museum of Natural History. Isis 103(3):460-490

Rudwick MJ (1988) The great Devonian controversy: the shaping of scientific knowledge among gentlemanly specialists. University of Chicago Press, Chicago

Sepkoski D (2012) Rereading the fossil record: the growth of paleobiology as an evolutionary discipline. University of Chicago Press, Chicago

Sepkoski D (2013) Towards "A Natural History of Data": evolving practices and epistemologies of data in paleontology, 1800-2000. J Hist Biol 46(3):401-444

Sepkoski D, Ruse M (eds) (2009) The paleobiological revolution: essays on the growth of modern paleontology. University of Chicago Press, Chicago

Sterelny K (2003) Dawkins vs. Gould. Icon, Cambridge

Turner DD (2004) The past the tiny: historical science and the abductive arguments for realism. Stud Hist Philos Sci Part A 35(1):1-17

Turner D (2005) Local underdetermination in historical science. Philos Sci 72(1):209-230

Turner D (2007) Making prehistory: historical science and the scientific realism debate. Cambridge University Press, Cambridge

Turner D (2011) Paleontology: a philosophical introduction. Cambridge University Press, Cambridge

Turner DD (2014) Philosophical issues in recent paleontology. Philos Compass 9(7):494-505

Turner DD (2019) In defense of living fossils. Biol Philos. https://doi.org/10.1007/s10539-019-9678-y

Wylie A (1999) Rethinking unity as a "working hypothesis" for philosophy of science: how archaeologists exploit the disunities of science. Perspect Sci 7(3):293-317

Wylie CD (2015) 'The artist's piece is already in the stone': constructing creativity in paleontology laboratories. Soc Stud Sci 45(1):31-55 
Wylie CD (2019) Overcoming the underdetermination of specimens. Biol Philos. https://doi.org/10.1007/ s10539-019-9674-2

Publisher's Note Springer Nature remains neutral with regard to jurisdictional claims in published maps and institutional affiliations. 